\title{
Risk Factors for Cardiovascular Diseases Among Urban Schoolchildren from Affluent Families
}

\author{
Ahmed D \\ Medical College for Women \& Hospital (MCW\&H), Dhaka, Bangladesh \\ e-mail: dilruba.ahmedm16@gmail.com
}

\begin{abstract}
Smoking, physical inactivity, obesity, raised blood pressure, low dietary intake of vegetables and fruits have been identified as risk factors for cardiovascular diseases. The study was aimed to find out the extent of risk factors for cardiovascular diseases among adolescent schoolchildren from affluent families of Dhaka city. This cross sectional study was done among 386 students of two English medium high schools during July 2006 to June 2007. Sixty one percent of the sample was boys. The children were of $10-18$ years age group (mean $=13.5$ years). Half of the parents had postgraduate education, fathers mostly businessmen and service holders and mothers were housewives. Moderate physical inactivity at leisure was found among $51 \%$ of the study population. Association between moderate physical activity (MPA) at leisure and gender was statistically significant $(p<0.001)$. Furthermore, $34 \%$ of the children spent 3 hours or more watching TV and /or using computer in a day. A little over $16 \%$ of the children were overweight and $8.5 \%$ obese. 'Ever smoked' were $16.5 \%$ males and $4.0 \%$ females. Association between ever smoked and gender was statistically significant $(p<0.001)$. Moreover, $51 \%$ children took fruits and 69\% took vegetables daily in their diet. Association between intake of fruits and vegetables and gender was not significant. Considering the high level of cardiovascular risk factors among adolescents, in terms of inactivity, overweight, obesity and smoking, population-wide life-style interventions specially focused on adolescents are thus recommended.
\end{abstract}

Keywords: Risk Factors, Cardiovascular diseases, Adolescents

\section{Introduction}

Over the past two centuries, the industrial and technological revolutions and their associated economic and social transformations have resulted in dramatic shifts in the diseases responsible for illness and death. ${ }^{1}$ Noncommunicable diseases (NCDs) are assuming increasing importance among the adult population in both developed and developing countries including Bangladesh. Cardiovascular diseases (CVDs) and cancer are at present the leading causes of death in developed countries, accounting for $70-75 \%$ of total deaths. Developing countries are now warned to take appropriate steps to avoid the "epidemics" of non-communicable diseases likely to come with socio-economic and health development. ${ }^{2}$

Smoking, alcohol, physical inactivity, obesity, raised blood pressure, dietary fats or blood lipids and blood glucose have been identified as risk factors for cardiovascular diseases. There is strong evidence that smoking, blood pressure and cholesterol are the cause of at least two thirds of heart attacks and strokes. ${ }^{3}$ Risk factors for CVDs, when detected in school children are predictive of coronary disease. When risk factors are detected in a significant proportion of children it predicts an increase of CVD in that population in future. The possibility of preventing the "appearance" of risk factors makes it possible to halt the emergence of CVDs. It is evident that atherosclerotic and hypertensive processes start in childhood. ${ }^{4}$ Prospective and retrospective studies have shown that CVD risk factors including obesity, the lipid profile, unhealthy diets and sedentary lifestyle, have their roots in childhood and tend to track into adulthood. ${ }^{5-8}$ Early identification and intervention of variables related to CVD in children are essential for minimizing the risk of developing the disease in later life. ${ }^{9}$ Adolescents are $22 \%$ of total population. ${ }^{10}$ Adolescents, particularly from the affluent section of the society, are following western life-styles. Over 
the last few decades Dhaka, the capital city of Bangladesh has been experiencing rapid urbanization and industrialization.

Only a few studies has been done on risk factors of CVD among Bangladeshi adults. ${ }^{11-12}$ But so far no study on children has been conducted in the country. The study aimed to find out the extent of behavioral risk factors for CVD, among children of affluent society in Dhaka. Findings of this study will be a step forward in this mostly unexplored area, and provide information for future studies.

\section{Materials and Methods}

This descriptive cross-sectional study was conducted among 386 children of 10-18 years age group of class VI to X during July 2006 to June 2007, in two English medium schools which included an autonomous, semigovernment school and a private school in Dhaka city. Students present at school on the day of interview and willing to participate in the study were included. Data were collected through face-to-face interviews and measurements were taken by the researcher herself and her two trained assistants.

The physical activity of the respondents was assessed by using the Global Physical Activity Questionnaire (GPAQ) in a modified form to make it suitable for schoolchildren. It included all activities throughout everyday life of a schoolchild and comprised of schoolwork, leisure-time activity and sedentary time. The physical activities were categorized into vigorous, moderate and sedentary.

Referring to the study, frequency of TV watching and computer use were calculated separately and included in the sedentary time. Children watching television or using computer for three hours or more per day or not participating in at least 30 minutes of moderate intensity physical activity per day were considered as physically inactive. ${ }^{13}$

Overweight and obese were expressed in terms of body mass index (BMI). For children overweight and obesity has been defined as an age and gender specific BMI of at or above the $85^{\text {th }}$ and $95^{\text {th }}$ percentile respectively and underweight as below the $3^{\text {rd }}$ percentile, based on the revised Center for Disease Control and
Prevention growth charts for boys and girls. After calculation of BMI for each child, the BMI value was plotted on the CDC BMI for-age growth chart to find out the percentile ranking of the respective respondent.

\section{Results}

Among 386 respondents majority (61.4\%) were males. Mean age was 13.5 years with a standard deviation (SD) of \pm 1.67 , and the children were from affluent families. Majority of the parents had postgraduate education, $53.6 \%$ were of them, fathers and $48.7 \%$ mothers. Majority of the fathers were businessmen $(36.3 \%)$ followed by government service $(28.5 \%)$. Most of the mothers $(73.1 \%)$ did household works only.

Only $4.7 \%$ children did vigorous physical activity (VPA) at school, mostly (3.9\%) males. Association between VPA at school and gender was statistically significant $(p<0.05)$. About $23 \%$ of the children were engaged in VPA at leisure, of whom majority (20\%) were males. Association between VPA at leisure and gender was found to be statistically highly significant $(p<0.0001)$ (table I).

Table I: Vigorous physical activity (VPA) ( $\mathrm{n}=386)$.

\begin{tabular}{lcccc}
\hline Variables & $\begin{array}{c}\text { Male } \\
\mathrm{N}(\%)\end{array}$ & $\begin{array}{c}\text { Female } \\
\mathrm{N}(\%)\end{array}$ & $\begin{array}{c}\text { Total } \\
\mathrm{N}(\%)\end{array}$ & $\boldsymbol{p}$ \\
\hline At school & & & & \\
No & $222(57.5)$ & $146(37.8)$ & $368(95.3)$ & 0.05 \\
Yes & $15(3.9)$ & $3(0.8)$ & $18(4.7)$ & \\
At leisure & & & & \\
No & $160(41.5)$ & $138(35.8)$ & $298(77.3)$ & 0.00 \\
Yes & $77(19.9)$ & $11(2.8)$ & $88(22.7)$ & \\
\hline
\end{tabular}

A little above a quarter of the study population, $27.2 \%$ performed moderate physical activity (MPA) at school of which about $18 \%$ were males and $9 \%$ females. No significant association was observed between moderate physical activity (MPA) at school and gender ( $p$ $>0.05)$. MPA at leisure was performed by almost half $(49 \%)$ of the subject, of whom $35 \%$ were males and $14 \%$ were females. Association between MPA at leisure and gender and was found to be statistically highly significant $(p<0.0001)$ (table II).

Table II: Moderate physical activity (MPA) $(n=386)$.

\begin{tabular}{lccc}
\hline \multicolumn{1}{c}{ Variables } & $\begin{array}{c}\text { Male } \\
\mathbf{N}(\%)\end{array}$ & $\begin{array}{c}\text { Female } \\
\mathbf{N}(\%)\end{array}$ & $\boldsymbol{p}$ value \\
\hline At school & & & \\
No & $168(43.5)$ & $113(29.3)$ & 0.2870 \\
Yes & $69(17.9)$ & $36(9.3)$ & \\
At leisure & & & \\
No & $104(26.9)$ & $94(24.4)$ & 0.000238 \\
Yes & $133(34.5)$ & $55(14.2)$ & \\
\hline
\end{tabular}


It was found that $34 \%$ watched TV and/or used computer for three hours or more per day. Mean time spent for watching TV and/or using computer per day for males was 135.27 minutes $(\mathrm{SD} \pm 99.18)$ and for females was 125.48 minutes $(S D \pm 104.41)$ (figure1)

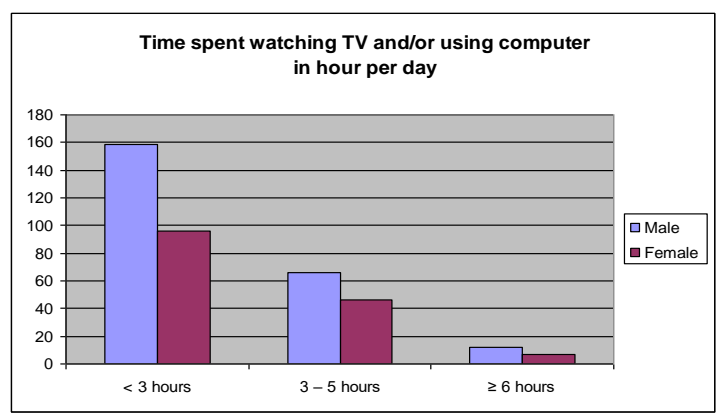

Figure 1: Time spent watching TV and/or using computer in hour per day.

Fifty one percent of the children took fruits. Association between intake of fruits and gender and was not significant. Almost $69 \%$ children took vegetables in their diet. Chi- square test for association between intake of vegetables and gender was also found to be not significant $(p>$ 0.05) (table III)

Table III: Distribution of intake of fruits and vegetables by gender.

\begin{tabular}{cccc}
\hline $\begin{array}{c}\text { Intake of } \\
\text { fruits } \\
\text { and vegetables }\end{array}$ & $\begin{array}{c}\text { Male } \\
\mathbf{N}(\%)\end{array}$ & $\begin{array}{c}\text { Female } \\
\mathbf{N}(\%)\end{array}$ & $\boldsymbol{p}$ value \\
$\quad \begin{array}{l}\text { Fruits } \\
\text { Yes }\end{array}$ & $123(51.9)$ & $75(50.3)$ & 0.764844 \\
$\quad$ No & $114(48.1)$ & $74(49.7)$ & \\
Vegetables & & & \\
$\quad$ Yes & $160(67.5)$ & $105(70.5)$ & 0.54177 \\
No & $77(32.5)$ & $44(29.5)$ & \\
\hline
\end{tabular}

Distribution of respondents by ever smoked status showed that about $11.6 \%$ of the children were 'ever smokers' (girls 4\% and males $16.5 \%$ ). Association between ever smoked and gender was found to be statistically highly significant ( $p<$ 0.001) (figure 2).

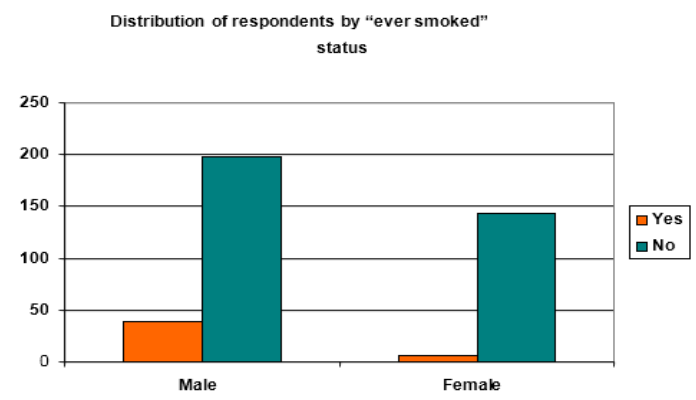

Figure 2: Distribution of respondents by "ever smoked" status.
Of the study population, $16.3 \%$ were overweight and $8.5 \%$ were obese. Also $6.5 \%$ of the children were underweight. Among boys, 20.2\% were overweight and $9.3 \%$ obese, and the girls $10.1 \%$ overweight and $7.4 \%$ were obese. Furthermore, $7.2 \%$ males and $5.3 \%$ females were found to be underweight (table IV).

Table IV: Categorization of weights of respondents by BMI percentiles.

\begin{tabular}{|c|c|c|c|}
\hline \multirow[b]{2}{*}{$\begin{array}{l}\text { Category of Weight } \\
\text { (Percentiles) }\end{array}$} & \multicolumn{2}{|c|}{ Gender } & \multirow[b]{2}{*}{$\begin{array}{l}\text { Total } \\
\text { N }(\%)\end{array}$} \\
\hline & $\begin{array}{l}\text { Males } \\
\mathrm{N}(\%)\end{array}$ & $\begin{array}{c}\text { Females } \\
\mathrm{N}(\%)\end{array}$ & \\
\hline $\begin{array}{l}\text { Underweight } \\
\left(<3^{\text {rd }} \text { percentile }\right)\end{array}$ & $\begin{array}{c}17 \\
(7.2 \%)\end{array}$ & $8(5.3 \%)$ & $25(6.5 \%)$ \\
\hline $\begin{array}{l}\text { Normal weight } \\
\left(3^{\text {rd }} \text { percentile }-<85^{\text {th }}\right. \\
\text { percentile })\end{array}$ & $\begin{array}{c}150 \\
(63.3 \%)\end{array}$ & $\begin{array}{c}115 \\
(77.2 \%)\end{array}$ & $\begin{array}{c}265 \\
(68.7 \%)\end{array}$ \\
\hline $\begin{array}{l}\text { Overweight } \\
\left(85^{\text {th }} \text { percentile }-<95^{\text {th }}\right. \\
\text { percentile })\end{array}$ & $\begin{array}{c}48 \\
(20.2 \%)\end{array}$ & $15(10.1 \%)$ & $\begin{array}{c}63 \\
(16.3 \%)\end{array}$ \\
\hline $\begin{array}{l}\text { Obese } \\
\left(\geq 95^{\text {th }} \text { percentile }\right)\end{array}$ & $\begin{array}{c}22 \\
(9.3 \%)\end{array}$ & $11(7.4 \%)$ & $33(8.5 \%)$ \\
\hline Total & $\begin{array}{c}237 \\
(100.0 \%)\end{array}$ & $\begin{array}{c}149 \\
(100.0 \%)\end{array}$ & $\begin{array}{c}386 \\
(100 \%)\end{array}$ \\
\hline
\end{tabular}

\section{Discussion}

This study showed that $61.4 \%$ of the children were boys. In Bangladesh, the male and female ratio is 105:100 in adult population. ${ }^{14}$ Here the ratio was about 159:100. The mean age was 13.5 years \pm 1.67 , ranging from $10-18$ years. According to the world Health Organization, the study population was adolescent. ${ }^{15}$ The background of the children indicated that they are from affluent families. ${ }^{9}$ Majority of the parents were highly educated. Although nearly half of the mothers were highly educated, most of them $(73.1 \%)$ did household works only.

The physical activities were categorized into vigorous, moderate and sedentary. Physical inactivity is an independent risk factor for CVD as well as for high blood pressure, high cholesterol levels and obesity. Among adults, higher levels of physical activity are associated with a reduced incidence of coronary artery disease and hypertension. ${ }^{16}$ Physical activity is an exceptionally common modifiable risk factor for CVD. Several American studies showed that lack of sufficient physical activity is endemic among children. Only a minority of schoolchildren have daily physical education classes, while walking and bicycling by children has declined. In contrast, the time spent in sedentary activities (television, video games, computers) has dramatically increased. ${ }^{17}$ For primary prevention, the U.S. Surgeon General 
recommended that every adult should accumulate 30 minutes of moderately intense physical activity on most, if not all, days of the week. ${ }^{18}$ Such recommendation could be applied to the study children.

This study revealed that one-fifth of the children had physical education classes in schools for 30 minutes or more per week. Vigorous Physical Activity (VPA) at school was done by only $4.7 \%$ of the schoolchildren. Near about onefourth were engaged in VPA at leisure, of them majority (20\%) were males. Association between VPA at leisure and gender was found to be statistically highly significant. A little over one-fifth did VPA for 30 minutes or more at leisure per day. On an average, males performed 21.58 minutes more of VPA at leisure than females. Kimm SY et al found in their study that by age $16,31 \%$ of white girls and $56 \%$ of black girls reported that they did not engage in any physical activity. ${ }^{19}$ This study also shows VPA at school among girls to be negligible $(0.8 \%)$. Only $27.2 \%$ of the children performed moderate physical activity at school. Only $11.4 \%$ of the children spent 30 minutes or more for MPA at school per day. No association was found between MPA at school and gender. Almost half of the children performed moderate physical activity at leisure. Association between MPA at leisure and gender was statistically highly significant. On average, males spent 22.18 minutes more for MPA at leisure than females. It is also evident that $51 \%$ are physically inactive at leisure.

A study among Iranian adolescents revealed that the two most prevalent CVD risk factors were physical inactivity $(66.6 \%)$ and dyslipidemia $(23.7 \%)$. In this study, physical inactivity in children was lower than the Iranian children. ${ }^{13}$ In this study, $51 \%$ of the children did not perform MPA at leisure, which is some extent consistent with the Centers for Diseases Control and Prevention, where as $61.5 \%$ of children between the ages of 9-13 years do not participate in any organized physical activity during their non-school hours. ${ }^{20}$

The present study also showed that one-third of the children were sedentary, according to TV watching/computer using criteria set in this study. More than half of the children took fruits and almost $69 \%$ took vegetables in their diet.
Association between intake of fruits and vegetables and gender was not significant. Eating at least 5 portions per day of a variety of fruits and vegetables is generally recommended for maintaining cardiovascular health. ${ }^{21}$ But in this study, the frequency of intake of vegetables and fruits was not analyzed.

About 3\% of the children were currently smokers, all were boys. Also one in five children were in the 'ever smoked' category. An Iranian study found that smoking among boys and girls was $5.7 \%$, which is higher than this study. ${ }^{7}$ Most smokers acquire their habit during their teenage. ${ }^{22}$ The children who have smoked in the past are at risk of smoking again.

Among the children $16.3 \%$ were overweight, boys twice as much as girls. Also regardless of gender $8.5 \%$ were obese. Interestingly, it was found that $6.5 \%$ of the children were underweight. Jonathan M Sorof and colleagues, found $11 \%$ of the Asian children aged 6-19 years as obese. ${ }^{23}$ This study revealed that obesity of this group of children is higher than the American Asian children. The Bogalusa Heart Study found prevalence of overweight (using BMI of $85^{\text {th }}$ percentile on CDC growth charts) ranged from $29 \%-33 \%$ for the 4 gender/race groups. ${ }^{21}$ The result of this study (also using the BMI of $85^{\text {th }}$ percentile) is quite lower than the Bogalusa study.

\section{Conclusion}

Schools should have sessions on physical activity and nutrition, including awareness development about risks of overweight or obesity and calorie-dense fast food. Furthermore, students should be encouraged to maintain a high level of physical activity in their daily life, with particular attention to the adolescents.

Acknowledgements: The author gratefully acknowledges the support of the WHO and the BMRC for the grant for the study. Thanks also to Research Assistants and the school authorities for their support and cooperation. I would like to express my special gratitude to Mohammad Moniruzzaman Khan, Assistant Programmer, MCW\&H for his immense support in preparing the manuscript. 


\section{References}

1. Gaziano JM. Global Burden of Cardiovascular Disease. In: Douglas PZ, Peter L, Robert OB, Eugene B, editors. Braunwald's Heart Disease- A textbook of Cardiovascular Medicine. $7^{\text {th }}$ ed. Philadelphia, USA: Elselvier Saunders. 2005. P. 1-19.

2. Park K. Park's Textbook of Preventive and Social Medicine. $18^{\text {th }}$ ed. Jabalpur India: M/s Banarasidas Bhanot, Jan 2005. p. 285-93.

3. Bonita R, de Courten M, Dwyer T, Jamrozik K, Winkelmann R. Surveillance of risk factors for noncommunicable diseases: The WHO STEPwise Approach. Summary. Geneva. World Health Organization. 2001.

4. Zipes DP, Libby P, Bonow RO, Braunwald E, editors. Braunwald's Heart Disease, A Textbook of Cardiovascular Medicine. $7^{\text {th }}$ ed. Saunders Elsevier, 2005. p. 962-63.

5. Guo SS, Huang C, Demerath E, Towne B, Chumlea WC, Siervogel RM. Body mass index during childhood, adolescence and young adulthood in relation to adult overweight and adiposity: the Fels Longitudinal Study. Int J Obes. 2000; 24: 1628-35.

6. Eriksson JG, Forsen T, Tuomilehto J, Osmond C, Barker DJ. Early growth and coronary heart disease in later life: longitudinal study. BMJ, 2001; 322: 949-53.

7. Kelder SH, Peryy CL, Klepp KI, Lytle LL. Longitudinal tracking of adolescent smoking, physical activity and food choice behaviors. Am J Public Health. 1994; 84: 1121-26.

8. Beaglehole R. Cardiovascular diseases in developing countries, an epidemic that can be prevented. BMJ 1992; 305: 1170-71.

9. Yannis M, Maria D, George M, Bike K, Haydar S, Yasar K, et al. Cardiovascular disease risk factors among children of different socioeconomic status in Istanbul, Turkey: Directions for public health and nutrition policy. Lipids Health Dis. 2004; 3: 11 .

10. Statistical Pocketbook of Bangladesh 1997. Bangladesh Bureau of Statistics, Planning Division, Ministry of Planning, Govt. of the Peoples Republic of Bangladesh, Dhaka 1998.

11. Zaman MM, Rouf MA. Prevalence of hypertension in a Bangladeshi adult population. J Hum Hypertens. 1999; 13: 547-9.

12. Zaman MM. Yoshiike N, Rouf MA, Syeed MH, Khan MR, Haque $S$ et al. Cardiovascular risk factors: distribution and prevalence in a rural population of Bangladesh. J Cardiovasc Risk 2001; 8: 103-08.
13. Roya K, Gholam HS, Ali AT, Manijeh K, Hamid RR, Masoumeh $S$ et al. Cumulative prevalence of risk factors for atherosclerotic cardiovascular diseases in Iranian adolescents: IHHP-HHPC. J Pediatr (Rio J) 2005; 81.

14. Statistical Pocketbook of Bangladesh 2004. Bangladesh Bureau of Statistics, Planning Division, Ministry of Planning, Govt. of the Peoples Republic of Bangladesh. Dhaka 2006.

15. WHO. Physical status: the use \& interpretation of anthropometry. Report of a WHO Expert Committee. World Health Organ Tech Rep Ser. 1995; 854:1-452.

16. Physical Activity and Cardiovascular Health. NIH Consensus development panel on Physical Activity and Cardiovascular Health. JAMA. 1996; 276: 241-46.

17. J. Michael G, Jo Ann EM, Paul MR. Primary and Secondary Prevention of Coronary Heart disease. In: Douglas PZ, Peter L, Robert OB, Eugene B, editors. Braunwald's Heart Disease- A textbook of Cardiovascular Medicine. $7^{\text {th }}$ ed. Philadelphia, USA: Elselvier Saunders. 2005. p. 1057-84.

18. Physical Activity and Health: A Report of the Surgeon General. Washington, DC, U.S. Department of Health and Human Services, Centers for Disease Control and Prevention. 1996.

19. Kimm SY, Glynn NW, Kriska AM, Barton BA, Kronsberg SS, Daniels SR, et al. Decline in physical activity in black girls and white girls during adolescence. N Engl J Med. 2002; 347: 709-15.

20. Center for Disease Control and Prevention. Physical activity levels among children aged 9-13 years--United States, 2002. MMWR Morb Mortal Wkly Rep. 2003; 52: 785-88.

21. Katzmarzyk PT, Srinivasan SR, Chen W, Malina RM, Bouchard C, Berenson GS. Body Mass Index, Waist Circumference, and Clustering of Cardiovascular Disease Risk Factors in a Biracial Sample of Children and Adolescents. Pediatrics. 2004; 114: 198-205.

22. Maureen TC, Thomas SI. Principles of Disease Prevention. In: Eugene B, Anthony SF, Dennis LK, Stephen LH, Dan LL, J Larry J, editors. Harrison's Principles of Internal Medicine. $15^{\text {th }}$ ed. USA: McGraw-Hill Companies Inc; 2001. p. 46-49.

23. Sorof JM, Lai D, Turner J, Poffenbarger T, Portman RJ. Overweight, ethnicity, and the prevalence of hypertension in school-aged children. Pediatrics. 2004; 113(3 Pt 1): 475-82. 